\title{
Sleep status of medical students of a private medical college in Kerala
}

\author{
Kumar Singh R.. ${ }^{1 *}$, Thomas A. ${ }^{2}$, Chollankil Hariharan $\mathrm{H}^{3}{ }^{3}$, Antherjanam Sreedharan $\mathrm{D}^{4}$, \\ Padmanabhan G. ${ }^{\mathbf{5}}$, Antony R. ${ }^{\mathbf{6}}$ \\ DOI: https://doi.org/10.17511/ijphr.2016.i4.02
}

1* Rajiv Kumar Singh, Associate Professor, Department of Community Medicine, Melmaruvathur Adhiprashakthi Institute of Medical Sciences, Melmaruvathur, Tamil Nadu, India.

2 Ann Mary Thomas, Assistant Professor, Department of Community Medicine, Sree Narayana Institute of Medical Sciences (SNIMS), Ernakulam, Kerala, India.

3 Harsha Chollankil Hariharan, Assistant Professor, Department of Community Medicine, Sree Narayana Institute of Medical Sciences, Kunnukara, Kerala, India.

4 Devaki Antherjanam Sreedharan, Assistant Professor, Department of Community Medicine, Sree Narayana Institute of Medical Sciences, Kunnukara, Kerala, India.

5 Gopalakrishnan Padmanabhan, Associate Professor, Department of Community Medicine, Sree Narayana Institute of Medical Sciences, Kunnukara, Kerala, India.

6 Raju Antony, Professor \& Head of the Department, Department of Community Medicine, Sree Narayana Institute of Medical Sciences, Kunnukara, Kerala, India.

Objective: Sleep is very important for healthy, efficient and happy life of every person. Medical students, being future doctors, need to have good rest and learn to take good care of themselves if they have to serve people efficiently in future. This subject, of quality of sleep among medical students, has not been researched in India. Design: Cross sectional study was done on medical students. Subjects: $20 \%$ of randomly selected students from five batches, a total of 100 students. Methods: Pittsburgh Sleep Quality Index (PSQI) form was administered to the students. Data was tabulated and analysed using Microsoft Excel. Scoring was done using PSQI Microsoft Access database software. Results: Out of 100, 53 (53\%) students showed poor quality sleep with Global PSQI score $>5$. Though only $5 \%$ felt their sleep was bad, $87 \%$ were found to have bad or worse sleep efficiency scores. Conclusions: Future doctors must follow good sleep hygiene and habits to ensure positive health, to ensure a long life full of energy. This subject needs to be studied further.

Keywords: Deprivation, PSQI, Sleep hygiene, Sleep quality

Corresponding Author

Rajiv Kumar Singh, Associate Professor, Department of Community Medicine, Melmaruvathur Adhiprashakthi Institute of Medical Sciences, Melmaruvathur, Tamil Nadu, India. Email: rajiv101@gmail.com

\section{How to Cite this Article}

Singh RK, Thomas AM, Hariharan HC, Sreedharan DA, Padmanabhan G, Antony R. Sleep status of medical students of a private medical college in Kerala. Public Health Rev Int J Public Health Res. 2016;3(4):147-155.

Available From

https://publichealth.medresearch.in/index.php/ijphr/ article/view/45
To Browse

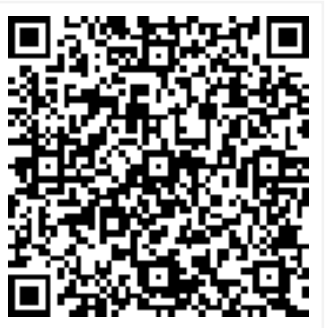

Manuscript Received 2016-06-24

Conflict of Interest No
Review Round 1 2016-07-08

Funding
Review Round 3

eview Round 2

Ethical Approval

Yes $8 \%$
Plagiarism X-checker

Accepted 2016-08-05

(C) 2016 by Rajiv Kumar Singh, Ann Mary Thomas, Harsha Chollankil Hariharan, Devaki Antherjanam Sreedharan, C 2016 by Rajiv Kumar Singh, Ann Mary Thomas, Harsha Chollankil Hariharan, Devaki Antherjanam Sreedharan,
Gopalakrishnan Padmanabhan, Raju Antony and Published by Siddharth Health Research and Social Welfare Society. This is an
Open Access article licensed under a Creative Commons Attribution 4.0 International License https://creativecommons.org/licenses/by/4.0/ unported [CC BY 4.0]. 


\section{Introduction}

Sleep is important for memory consolidation and learning and also in order to avoid health problems and psychiatric disorders. Recent reviews have indicated an important relationship between sleep pattern with learning abilities and consequent academic performance [1. 2]. Entering medical school presents students with increased academic pressures and stress levels, and these new demands instigate changes in sleep and work habits [3]. Research shows that although medical students exhibit good health behaviors compared with other young adults, they also demonstrate significant changes to these habits as their education continues [4].

The reduced sleep duration in medical students triggers an irregular pattern of sleep-wakefulness cycle, which is characterized by large sleep latency on weekends and by short sleep duration on weekdays. This irregular cycle usually increases the incidence of sleep disturbances and daytime dysfunction [5]. Pittsburgh Sleep Quality Index (PSQI) is the gold standard questionnaire for assessing subjective sleep quality and has been validated in both clinical populations and non-clinical population, including college and graduate students [6-8].

Medical students are future physicians. Sleep disturbances affect both physical as well as mental health and their performance. So it is important to make them aware of their sleep status and encourage them to form strategies that would help them to keep academic demands and sleep hygiene going hand in hand. Since we could not find any other study done on sleep of medical students in India, this study was conducted as a pilot study to assess the sleep status of medial students in India and did not take into consideration other factors affecting their sleep. The basic purpose was to find a baseline for Indian students and inform them about the importance of good sleep if they have to live and work as doctors on a long term basis.

\section{Material and Methods}

After obtaining the approval to conduct the study from Institutional Research Committee and Institutional Ethics Committee, a cross sectional study was conducted to assess the sleep status of medical students in a private medical college in Kerala in November 2015.
A random sample of $20 \%$ (20) students was taken from each of the five batches in attendance at the college, giving us a sample of 100 students. PSQI questionnaire was used to collect data and was scored using PSQI Microsoft Access database scoring software. The collected data were tabulated and analysed using MS Excel. Since the scope of this pilot study was to collect data on sleep status only, data on various factors that might affect the sleep was not collected.

\section{Results}

In our sample of 100 medical students, there were $69(69 \%)$ females and $31(31 \%)$ males and the subject were in the age range of 17 to 26. Each of the seven components of Pittsburgh Sleep Quality was assessed and the individual scores were used to calculate the Global Sleep Quality Score. Sleep latency is the length of time from wakefulness to sleep i.e. to the lightest of non-REM sleep, or simply it is the time taken to fall asleep. Average duration in hours of sleep of medical students were 6.65, Standard Deviation (SD) of 1.196 hours. Mean latency period of falling asleep was 14.92 minutes, SD of 13.386 minutes. None of the students had to take medicine to go to sleep.

Table 1 shows the 30 minute sleep latency among the students. It shows that $33 \%$ have experienced inability to fall asleep within 30 minutes at least once during last one month and $4 \%$ experience this 3 or more times a week.

Table-1: Cannot Sleep within 30 Minutes. $\mathbf{N}=\mathbf{1 0 0}$

\begin{tabular}{|l|l|l|l|}
\hline \multicolumn{1}{|c|}{ Cannot Sleep } & Scores & Frequency & Percent \\
\hline Not during the past month & 0 & 67 & 67.0 \\
\hline Less than once a week & 1 & 18 & 18.0 \\
\hline Once or twice a week & 2 & 11 & 11.0 \\
\hline Three or more times a week & 3 & 4 & 4.0 \\
\hline Total & & 100 & 100.0 \\
\hline
\end{tabular}

Table-2: Sleep Latency Scores Frequency Distribution, $\mathbf{N}=100$.

\begin{tabular}{|l|l|l|l|}
\hline & \multicolumn{1}{|c|}{ Scores } & \multicolumn{1}{c|}{ Frequency } & \multicolumn{1}{c|}{ Percent } \\
\hline Better & 0 & 62 & 62.0 \\
\hline Good & 1 & 28 & 28.0 \\
\hline Bad & 2 & 6 & 6.0 \\
\hline Worse & 3 & 4 & 4.0 \\
\hline Total & & 100 & 100.0 \\
\hline
\end{tabular}

The second step in finding the latency score is to add the individual scores of question 2 and $5 a$ of the questionnaire and assign a new scoring. 
This scoring is shown in Table 2 . Here only $10 \%$ had bad or worse scores indicating longer sleep latency. Table 3 shows Duration of Sleep.

Table- 3: Duration of Sleep, $\mathbf{N}=100$.

\begin{tabular}{|l|l|l|l|}
\hline \multicolumn{1}{|c|}{ Duration of Sleep } & Scores & Frequency & Percent \\
\hline Greater than or equal to 7 hours & 0 & 58 & 58.0 \\
\hline 6 to 7 hours & 1 & 29 & 29.0 \\
\hline 5 to 6 hours & 2 & 8 & 8.0 \\
\hline Less than 5 hours & 3 & 5 & 5.0 \\
\hline Total & & 100 & 100.0 \\
\hline
\end{tabular}

Table-4: Sleep Disturbance, $\mathbf{N}=100$.

\begin{tabular}{|l|l|l|l|}
\hline & \multicolumn{1}{|c|}{ Scores } & \multicolumn{1}{c|}{ Frequency } & \multicolumn{1}{c|}{ Percent } \\
\hline Better & 0 & 17 & 17.0 \\
\hline Good & 1 & 76 & 76.0 \\
\hline Bad & 2 & 7 & 7.0 \\
\hline Worst & 3 & 0 & 0.0 \\
\hline Total & & 100 & 100.0 \\
\hline
\end{tabular}

Table 4 shows sleep disturbance, only seven (7) students have bad sleep and none had worst sleep. Table 5 shows dysfunction in the day time due to lack of enthusiasm. Only 13 students considered it a significant problem. Table 6 shows day dysfunction due to sleepiness, i.e. trouble staying awake while engaging in social activities, driving or eating meals. Only eight (8) students showed bad or worse dysfunction due to day time sleepiness.

Table-5: Problem of Lack of Enthusiasm During Day. $\mathbf{N}=100$

\begin{tabular}{|l|l|l|l|}
\hline \multicolumn{1}{|c|}{ Problem Magnitude } & Scores & Frequency & Percent \\
\hline No Problem at All. & 0 & 52 & 52.0 \\
\hline Only a very Slight Problem & 1 & 35 & 35.0 \\
\hline Somewhat of a Problem & 2 & 12 & 12.0 \\
\hline A very big Problem & 3 & 1 & 1.0 \\
\hline Total & & 100 & 100.0 \\
\hline
\end{tabular}

Table-6: Day Dysfunction due to Sleepiness

\begin{tabular}{|l|l|l|l|}
\hline & \multicolumn{1}{|c|}{ Scores } & \multicolumn{1}{c|}{ Frequency } & \multicolumn{1}{c|}{ Percent } \\
\hline Better & 0 & 46 & 46.0 \\
\hline Good & 1 & 46 & 46.0 \\
\hline Bad & 2 & 7 & 7.0 \\
\hline Worse & 3 & 1 & 1.0 \\
\hline Total & & 100 & 100.0 \\
\hline
\end{tabular}

Table 7 shows the subjective sleep quality as felt by the subjects. Only five ( $5 \%$ ) feel their sleep was bad and none report very bad sleep.

Table- 7: Subjective Sleep Quality $\mathbf{N}=100$

\begin{tabular}{|l|l|l|l|}
\hline \multicolumn{1}{|c|}{ Subjective Sleep Quality } & Scores & Frequency & Percent \\
\hline Very Good & 0 & 39 & 39.0 \\
\hline Fairly Good & 1 & 56 & 56.0 \\
\hline
\end{tabular}

\begin{tabular}{|l|l|l|l|}
\hline Fairly Bad & 2 & 5 & 5.0 \\
\hline Very Bad & 3 & 0 & 0 \\
\hline Total & & 100 & 100.0 \\
\hline
\end{tabular}

Table-8: Frequency of Sleep Efficiency Scores (HSE- Habitual Sleep Efficiency)

\begin{tabular}{|l|l|l|l|}
\hline \multicolumn{1}{|c|}{ Habitual Sleep Efficiency } & Scores & Frequency & Percent \\
\hline Better & 0 & 12 & 12.0 \\
\hline Good & 1 & 1 & 1.0 \\
\hline Bad & 2 & 1 & 1.0 \\
\hline Worse & 3 & 86 & 86.0 \\
\hline Total & & 100 & 100.0 \\
\hline
\end{tabular}

Table 8 shows Habitual Sleep Efficiency Scores. Habitual sleep efficiency is the proportion of actual sleep duration to the time spent in bed. Actual duration of sleep may not be the same as the time spent in bed. Only $13 \%$ were found to have better or good sleep efficiency.

Table-9: Total PSQI Scores for the Students $\mathbf{N}=\mathbf{1 0 0}$

\begin{tabular}{|c|c|c|c|c|c|}
\hline Sleep Quality & Score & Frequency & $\begin{array}{l}\text { Class } \\
\text { Frequency }\end{array}$ & $\%$ & $\begin{array}{c}\% \text { for Sleep } \\
\text { Quality }\end{array}$ \\
\hline \multirow{5}{*}{$\begin{array}{l}\text { Good Quality } \\
\text { Sleep }\end{array}$} & 1 & 1 & \multirow[t]{5}{*}{47} & 1.0 & \multirow[t]{5}{*}{47} \\
\hline & 2 & 3 & & 3.0 & \\
\hline & 3 & 7 & & 7.0 & \\
\hline & 4 & 14 & & 14.0 & \\
\hline & 5 & 22 & & 22.0 & \\
\hline \multirow{7}{*}{$\begin{array}{l}\text { Poor Quality } \\
\text { Sleep }\end{array}$} & 6 & 13 & \multirow[t]{6}{*}{53} & 13.0 & \multirow[t]{6}{*}{53} \\
\hline & 7 & 16 & & 16.0 & \\
\hline & 8 & 14 & & 14.0 & \\
\hline & 9 & 5 & & 5.0 & \\
\hline & 10 & 4 & & 4.0 & \\
\hline & 11 & 1 & & 1.0 & \\
\hline & Total & 100 & 100 & 100.0 & 100 \\
\hline
\end{tabular}

Not a single student stated that they needed medication to help them to fall asleep. Table 9 show the Global PSQI scores. Score of six or more shows poor quality of sleep. Data clearly shows that $53 \%$ of subjects had poor quality sleep and only $47 \%$ showed good quality sleep.

\section{Discussion}

In our study 53 (53\%) of the study group had poor sleep quality. In a web based survey, among 314 medical students, $50.9 \%$ were reported to have poor sleep quality [3] and similarly among medical students of Hong Kong University 58\% showed to be poor sleepers [9]. In this study $33 \%$ of students experienced inability to fall asleep within 30 minutes and the average time taken to fall asleep, as reported by students, was 14.92 minutes. 
In a study conducted on Health students in Jordan, a slightly higher proportion of medical students $(48 \%)$ reported inability to fall asleep within 30 minutes and a much higher time of 25.12 minutes to fall asleep [10].

Present study shows that a significant proportion of students $(42 \%)$ slept less than seven (7) hours. This result is consistent with other studies conducted in Medical University of Taipei, Taiwan and Malaysia that showed that $46.9 \%$ and $48.8 \%$, respectively, sleeping less than seven (7) hours [11, 12].

In this study the average score of sleep disturbance in 0.92, ( 0 being the better score and 3 being the worse score) and hence $93 \%$ of students are suffering slight or no sleep disturbance. In a study in Jordan University, students had a sleep disturbance mean score of 1.33 [10]. This could have been due to the fact that the Jordanian study had an older student group with population ranging from 19 to 40 years, and difference in race, ethnicity, etc.

In this study 52 (52\%) students reported that they had 'No problem with lack of enthusiasm in the daytime'. On the contrary, study conducted by PeyPeng et al in Northern Malaysia, showed only $16.1 \%$ $(n=180)$ having 'No problem with lack of enthusiasm in the daytime'[13]. That is a very significant difference in two studies and we are not able to understand the reason for it.

In our study, $95 \%$ of students rated their sleep quality very good (39\%) or fairly good (56\%) and only $5 \%$ reported to have fairly bad or very bad sleep quality. But in another study conducted in Malaysia, among 799 medical students, 16.1\% reported fairly bad or very bad sleep quality [12].

This study found that, although sleep quality was rated good by majority, $87 \%$ had poor or worse sleep efficiency (Habitual Sleep Efficiency score or HSE). On the contrary, in a study conducted in health students in Jordan, $65 \%$ of students were found to have good sleep efficiency but majority of them reported poor sleep quality [10].

It seems that students from Jordan, though $65 \%$ had good sleep scores, like to complain more about their sleep quality; on the contrary in our study, Indian students from Kerala state had poor sleep quality but did not consider it a problem worth complaining about.
In this study all students denied a need to take medicine to go to sleep. But in a similar study conducted in medical students in Northern Malaysia, $3.85 \%(43, n=1118)$ students reported having to take medicine to help them sleep. In another study by Zailiniwati $3.9 \%$ reported using medication to sleep [12].

\section{Conclusion\& Recommendations}

This pilot study showed sleep problems need to be studied further as Indian Medical Students are living in denial of sleep problems and pushing themselves without any attempt to get a better sleep.

Health education is required among students so they understand the importance of good sleep, specially its role in better functioning of the brain, in terms of memory, academic performances, etc.

Even though majority of subjects (95\%) reported good subjective sleep quality, the sleep efficiency was worse for $86 \%$ and Global Sleep Score was found to be poor for more than half (53\%) of the study group. This contradiction shows that either majority of students are unaware of the situation or are too busy to notice it, due to pressure of academic work and achievement.

The study does not show sleep disturbances or disorders like sleep apnoea, snoring, etc. and the students are not taking any medication to fall asleep. The study have not gone into factors affecting sleep and sleep hygiene, was not inquired into.

Results clearly show majority do not have good overall sleep score, so further studies are needed on the issue of sleep and factors affecting it in India. This could avoid poor academic performances and even psychiatric disorders in later life. Health awareness classes and importance of having good sleep has to be stressed. These little things, like good sleep, we have to start taking care of if we have to further increase the life expectancy of the people to the level of developed countries.

\section{Acknowledgement}

The authors acknowledge the encouragement provided by our Principal Dr. (Commodore) MJ John and the help provided by House Surgeons, Dr. K. Fathima Shareefa, Dr. Karthika Jayasimhan, Dr. Krishnachandran B Varier, Dr. Mary Shinu Stalin and Dr. Melbit Thomas. 


\section{Reference}

01. BaHammam AS, Alaseem AM, Alzakri AA, Almeneessier AS, Sharif MM. The relationship between sleep and wake habits and academic performance in medical students- a crosssectional study. BMC Med Educ. 2012;Aug $1 ; 12 ; 61$ doi: 10 .

1186/1472-6920-12-61 [Crossref]

02. Giri PA, Baviskar MP, and Phalke DB. Study of sleep habits and sleep problems among medical students of Pravara Institute of Medical Sciences Loni, Western Maharashtra, India. Ann Med Health Sci Res. 2013 Jan-Mar;3(1)51-4. doi: $10.4103 / 2141-9248.109488$ [Crossref]

03. Cameron AB, Darbi LS, Tonya MP. Association between sleep hygiene and sleep quality in medical students. Behav Sleep Med. 2010;8(2)113-21.

[Crossref]

04. Frank E, Carrera JS, Elon L, Hertzberg VS. Basic demographics, health practices and health status of US medical students. American Journal of Preventative Medicine. 2006;31;499-505.

[Crossref]

05. Castro CP, Figueiredo FF, Lima GAF, et al. Evaluation of the sleep quality in medical students from Ribeirao, Preto, SP/ Brazil. Scholarly J Med. 2012 Jun;2(4)42-50.

[Crossref]

06. Buysse DJ, Reynolds CF, Monk TH, Berman SR, Kupfer DJ. The Pittsburgh Sleep Quality IndexA new instrument for psychiatric practice and research. Psychiatry Res. 1989 May;28(2)193213.

[Crossref]

07. Backhaus J, Junghanns K, Broocks A, Riemann D, Hohagen F. Test-retest reliability and validity of the Pittsburgh Sleep Quality Index in primary insomnia. J Psychosom Res. 2002 Sep;53(3)737-40.

[Crossref]

08. Carney CE, Edinger JD, Meyer B, Lindman L, Istre T. Daily activities and sleep quality in college students. Chronobiol Int. 2006;23(3)623-37.

[Crossref]
09. Lorna KPS, Wilson WST, Hon KL. Association of sleep hygiene related factors and sleep quality among university students in Hong Kong. Hong Kong Med J. 2010;16;180-5.

DOI: 10.1080/07420520600650695 [Crossref]

10. Suleiman K, Yates B, Jassem H, Aljhabeesh $S$, Abu-Shahroor L, Ali R. Sleep disturbances among Al-zaytoonah University in Jordan. Journal of Natural Sciences Research. 2013;3(12)39-46.

[Crossref]

11. Jiunn-Horng $K$, Shih-Ching $C$. Effects of an irregular bedtime schedule on sleep quality, daytime sleepiness and fatigue among university students in Taiwan. BMC Public Health. $2009 ; 9 ; 248$.

DOI: $10.1186 / 1471-2458-9-248$ [Crossref]

12. Zailiniwati $A H$, Teng $C L$, Chung YC. Daytime sleepiness and sleep quality among Malaysian medical students. Med J Malaysia. 2009 Jun;64(2)108-10.

[Crossref]

13. Lai PP, Say YH. Associated factors of sleep quality and behavior among students of two tertiary institution in northern Malaysia. Med J Malaysia. 2013 Jun;68(3)195-203. [Crossref] 